\title{
Fitness of Races 0 and 1 of Phytophthora parasitica var. nicotianae
}

M. J. Sullivan, National Weed Management Laboratory, USDA APHIS PPQ CPHST, 2301 Research Blvd., Suite 108, Fort Collins, CO 80526; T. A. Melton, Associate State Program Leader, AgNR/CRD, Cooperative Extension Service, North Carolina State University, Raleigh 27695-7602; and H. D. Shew, Department of Plant Pathology, P.O. Box 7903, North Carolina State University, Raleigh 27695

\begin{abstract}
Sullivan, M. J., Melton, T. A., and Shew, H. D. 2005. Fitness of races 0 and 1 of Phytophthora parasitica var. nicotianae. Plant Dis. 89:1220-1228.

Deployment of tobacco (Nicotiana tabacum) varieties with complete resistance to race 0 of Phytophthora parasitica var. nicotianae has led to a rapid increase in the field populations of race 1 in North Carolina. In a field study, population levels of race 1 decreased relative to race 0 when cultivars with partial resistance to both races were planted, suggesting that race 1 isolates were less fit than race 0 isolates. Experiments were conducted to quantify differences in aggressiveness and survivability of the two races. Tobacco varieties with low, moderate, or high levels of partial resistance were inoculated with 60 pathogen isolates, and symptom development was monitored for 3 weeks. Race 0 isolates were more aggressive than race 1 isolates on cultivars with moderate or high levels of partial resistance; incubation periods were shorter and root rot severity was greater with race 0 isolates. Isolates of race 1 , however, caused greater stunting of plants with moderate and high levels of partial resistance than race 0 isolates. Field microplots were infested with either a single race or an equal mixture of each race. Soil samples were collected at the end of two growing seasons and again the following spring. Pathogen populations declined from 40 to $80 \%$ during winter months, but population declines for race 0 were lower than for race 1 in each treatment over each winter. Race shifts from race 1 to race 0 that were observed in the presence of cultivars with partial resistance appear to be primarily the result of differences in aggressiveness of the races, with a possible minor effect of enhanced overwintering survival of race 0 compared with race 1 .
\end{abstract}

Additional keywords: black shank, oomycete

Black shank, caused by the soilborne pathogen Phytophthora parasitica var. nicotianae (syn. P. nicotianae var. nicotianae, $P$. nicotianae), is an economically important disease of cultivated tobacco (Nicotiana tabacum) throughout the southeastern United States and many production areas of the world $(11,22,25)$. Infection of roots, stems, and leaves can occur at any stage of plant growth, resulting in root necrosis, wilting, chlorosis, stem lesions, and stunting of plants $(12,22)$. Yield losses result in millions of dollars in lost revenue annually (25).

Black shank is managed by using an integrated approach that includes cultural practices, fungicides, and host resistance (25). The most practical and economical single method of controlling black shank, however, is the use of resistant cultivars. Cultivated N. tabacum and the wild species $N$. plumbaginifolia and $N$. longiflora have been used as sources of resistance. In

Corresponding author: M. J. Sullivan

E-mail: Melinda.J.Sullivan@aphis.usda.gov

Accepted for publication 8 July 2005 .

DOI: 10.1094/PD-89-1220

(C) 2005 The American Phytopathological Society
1931, Tisdale intraspecifically transferred black shank resistance to the $N$. tabacum cigar wrapper cultivar Florida 301 ('Fla. 301') (39). Until 1964, 'Fla. 301' was the resistant parent from which all black shank resistant cultivars were developed (22). The 'Fla. 301' type of resistance confers partial resistance that ranges from a low to a high level.

Single-gene resistance also has been incorporated interspecifically into $N$. tabacum cultivars from $N$. longiflora and $N$. plumbaginifolia, both of which confer complete resistance to race 0 of the black shank pathogen $(5,7,9,40)$. Four physiological races $(0,1,2$, and 3$)$ of $P$. parasitica var. nicotianae have been reported. These races are defined by their ability to infect cultivars with different resistance genes. Apple (3) first described a strain of $P$. parasitica var. nicotianae that was nonpathogenic to Nicotiana plumbaginifolia Viv as race 0 , and a strain that infected $N$. plumbaginifolia as race 1 . Race 1 isolates also can infect cultivars that have the gene from $N$. longiflora. Races 2, 3, and isolate 63 of $P$. parasitica var. nicotianae have also been reported in South Africa, Connecticut, and Karnataka, India, respectively $(24,29,32)$.

Race 0 has been the predominant race in the flue-cured area of North Carolina since the pathogen was introduced in 1931 (22). Although race 1 was observed in breeding nurseries in the 1960s, it was not observed widely in production areas until cultivars containing the single-gene ( $P h$ gene) type of resistance from $N$. plumbaginifolia were deployed in the 1990s $(8,17)$. Subsequently, black shank began to appear in fields planted to cultivars with the $P h$ gene. Testing revealed that wherever the disease appeared, race 1 was present. Deployment of this type of resistance continues to increase, and in 2003 it was present in an estimated $58 \%$ of the flue-cured production area in North Carolina (25).

The increase in race 1 in the flue-cured production areas and an effort to preserve the effectiveness of the $P h$ gene prompted a research study to ascertain the short- and long-term effects of $P h$ gene deployment on the race structure and population dynamics of the tobacco black shank pathogen (37). Four-year cultivar rotation studies were conducted in three North Carolina fields that differed in initial population structure according to race. In these studies, two partially resistant cultivars ('K326' and 'K346') and one completely resistant ( $P h$ gene) cultivar ('NC71') were cropped continuously or in various combinations of complete and partial resistance. In all three fields, when complete resistance was deployed continuously, the proportion of race 1 increased or continued to predominate relative to race 0 in the pathogen population. In sharp contrast, however, when either the low or high level of partial resistance was continuously deployed, the proportion of race 0 increased or continued to predominate relative to race 1 in the pathogen population. These results indicated that isolates of race 1 were less fit than isolates of race 0 when cultivars with partial resistance were planted. The authors speculated that the differences observed could be due to differences in aggressiveness (pathogenic fitness) or survival (ecological fitness) of isolates of the two races (37).

Variation in aggressiveness among isolates within Phytophthora species has long been recognized $(15,20,21,23,27,30,31,38)$. Previous studies also have indicated variation in aggressiveness within isolates of $P$. parasitica var. nicotianae $(1,2,10,13,26$, 28,42 ). Nolla (26) reported a weakly pathogenic strain (low aggressiveness) of $P$. parasitica var. nicotianae obtained from 
Sumatra, but concluded that the low level of disease produced was most likely due to the age of the culture. Powers and Lucas (28) reported a weakly pathogenic strain of $P$. parasitica var. nicotianae from North Carolina. Apple noted that over 200 isolates of the tobacco black shank pathogen obtained from 44 North Carolina counties, 8 states, and 5 foreign countries varied from weakly pathogenic on a susceptible cultivar to highly pathogenic on a moderately resistant cultivar $(1,2)$. Van Jaarsveld (42) also observed considerable variation in aggressiveness of South African isolates of $P$. parasitica var. nicotianae based on lesion length on 'Hicks' (susceptible) and 'TL33' (moderately resistant). On cultivars with low ('NC 2326'), moderate ('Burley 37'), or high ('Beinhart 1000-1') levels of partial resistance, however, there was little to no significant difference between lesion lengths of all isolates examined, including isolates of races 0 and 1 (42).

Development of black shank is related to initial inoculum density and level of partial resistance in the host $(16,18,34)$. Ferrin and Mitchell (16) noted that plant mortality was directly related to initial inoculum density for the moderately resistant 'Speight G-28', but not for the susceptible 'Hicks'. Since the differences observed in isolate fitness in a cultivarrotation study occurred on cultivars with partial resistance (37), initial inoculum densities may have played an important role in disease development and the resulting race shifts observed in those tests. Thus, survivability may be an important component of fitness for races of this pathogen.

Race 0 has long been anecdotally termed "more fit" than race $1(2,22)$. However, studies have not specifically examined fitness of races 0 and 1 of the black shank pathogen. The difference in fitness of races 0 and 1 of $P$. parasitica var. nicotianae observed in previous field studies could have been attributed to differences in pathogenic fitness (aggressiveness) or ecological fitness (survival), or both. The objectives of this study were to quantify differences in the aggressiveness and survivability of races 0 and 1 of $P$. parasitica var. nicotianae and to determine their relative role in the fitness of the two races of the pathogen.

\section{MATERIALS AND METHODS}

Aggressiveness study. Sixty isolates of $P$. parasitica var. nicotianae were chosen at random from plots planted in continuous culture to the flue-cured tobacco cultivars 'K 326' (low level of partial resistance), ' $\mathrm{K}$ 346' (high level of partial resistance), or 'NC 71' (complete resistance to race 0 and a low level of partial resistance) (37). The isolates included 20 race 0 isolates from ' $\mathrm{K} 326$ ' plots, 20 race 0 isolates from ' $\mathrm{K}$ 346 ' plots, and 20 race 1 isolates from ' $\mathrm{NC}$ 71 ' plots. All isolates were obtained from soil samples taken from a single field site during one sampling period (37). The purpose of choosing isolates from the same season and same year was to minimize variability and to eliminate the possibility of reduced pathogenicity that may occur due to the age of the culture (26). The isolates were collected in 2001 from a cultivar-rotation study in Edgecombe Co., $\mathrm{NC}$, at the Upper Coastal Plain Research Station using a soil assay method and a semi-selective agar medium. Soil samples from each plot were thoroughly mixed prior to assay. Multiple 1-g subsamples of soil were taken from each plot to obtain the desired 20 isolates. Each subsample was suspended in $25 \mathrm{ml}$ of deionized water and then dispensed, $5 \mathrm{ml}$ per plate, onto five plates of modified PARPH semiselective medium, containing V8 juice as the basal medium and amended with pentachloronitrobenzene, hymexazol, ampicillin, rifampicin, and pimaricin $(19,33)$. The race of each isolate was confirmed using a set of host differentials (37).

Four cultivars were used to assess variation in aggressiveness of $P$. parasitica var. nicotianae: 'Hicks' (susceptible), 'K 326' (low level of partial resistance), 'K 149' (moderate level of partial resistance), and 'K 346' (high level of partial resistance). Plants of each cultivar were seeded into a flat containing potting mix (Metro mix 220, The Scotts Company, Marysville, $\mathrm{OH})$ and allowed to grow 3 weeks. After 3 weeks, the plants were transplanted into cell packs $(72$ cells, $4 \times 4 \times 5 \mathrm{~cm})$ containing a 1:1:1 (vol/vol/vol) mixture of steampasteurized soil, Metro mix (W. R. Grace), and coarse builder's sand. All plants were watered daily, fertilized as necessary with 20-20-20 water-soluble fertilizer (Peter's), and allowed to grow an additional 7 to 10 days before a second transplant into a 10.16-cm-diameter pot $(11 \mathrm{~cm}$ depth, 400 $\mathrm{cm}^{3}$ volume) containing the same $1: 1: 1$ soil mixture used above.

Inoculum was prepared by placing oat grains sterilized by autoclaving at $121^{\circ} \mathrm{C}$ for $60 \mathrm{~min}$ on three consecutive days onto a 3-day-old carrot agar culture of each isolate of $P$. parasitica var. nicotianae collected from the soil assay. The oat grains were left on the cultures for 9 days at room temperature $\left(20\right.$ to $\left.23^{\circ} \mathrm{C}\right)$. Sixty oat grains were then removed from each plate using sterile technique and used as inoculum for the aggressiveness test. Five 5- to 6-week-old plants of each genotype were root-inoculated with each isolate in the greenhouse by placing three colonized oat grains into each $10.16-\mathrm{cm}$-diameter pot in a triangular pattern around the growing plant. Three approximately 5-cm-deep holes were made in a triangular pattern approximately $3 \mathrm{~cm}$ from the stem, and colonized oat grains were placed in each hole with sterilized forceps. Roots were not damaged prior to inoculation. Symptom development, including chlorosis, wilting, and lesion development, was recorded at $3,5,7,14$, and 21 days after inoculation.

Data on incubation period, severity index, stunting, and root rot were collected. Incubation period was determined as the time required for initial symptom development. Incubation period data also were converted into a severity index class that corresponded to the number of days required for the expression of symptoms after inoculation (2). The classes and the corresponding severity values were as follows: 3 days $=10,5$ days $=8,7$ days $=$ 6,14 days $=4,21$ days $=2$, and no symptoms at day $21=0$. In the calculation of the severity index for an isolate, the number of plants placed in each class was multiplied by the corresponding numerical value; these products were totaled and divided by the number of plants in each treatment. Thus, the severity indices reflect both the incidence of disease and how rapidly the disease developed on a given cultivar (2). Initial and final plant heights were measured, and the change in height relative to noninoculated control plants was used as an indication of stunting. After 21 days, all plant root systems were washed and assigned a root rot severity index from 1 to 7 , with: $1=$ none, $2=$ trace, $3=1$ to $5 \%, 4=6$ to $25 \%, 5=26$ to $50 \%, 6=51$ to $75 \%$, and $7=76$ to $100 \%$.

The experimental design was a randomized complete block with five replications for each isolate $\times$ variety treatment $(1,200$ plants per trial); plants in each rep were blocked by initial plant height. The experiment was repeated once. The first trial was conducted from June through July 2002, and the second trial was conducted from September through October 2002. Analysis of variance was performed on the severity index, root rot, and stunting data using the PROC GLM procedure of SAS (version 8e, SAS Institute, Cary, NC), and means separation was conducted using the Waller-Duncan $k$-ratio test $(k=100)$. Unless otherwise indicated, only significant $(P \leq 0.05)$ differences between treatment means are presented.

Survival study. A 3-year microplot experiment was established in May 2000 at the Central Crops Research Station in Clayton, NC, and continued through the spring of 2003. Plots $(75 \mathrm{~cm}$ diameter, 45 $\mathrm{cm}$ depth) were infested with either race 0 or race 1 (single race) or with an equal mixture of both races (mixed raced). Plots were infested by uniformly distributing pathogen-colonized oat grains $\left(\sim 50 \mathrm{~cm}^{3}\right.$ per plot) into each plot in late May 2000. Two isolates of $P$. parasitica var. nicotianae were used to infest all microplots: a race 0 isolate from Edgecombe Co., NC, and a race 1 isolate from Mitchell Co., NC. Each isolate was inoculated onto test plants prior to infestation to ensure that each isolate was highly aggressive on cultivars with various levels of partial resis- 
tance. Each of the single and mixed race plots received one of three treatments: 'K326' (low level of partial resistance), 'K346' (high level of partial resistance), or 'NC71' (complete resistance to race 0 and a low level of partial resistance) that were continuously cropped over the three growing seasons. Each race $\times$ cultivar treatment was replicated 16 times (single race) or 18 times (mixed race), and treatments were arranged in a completely randomized experimental design. Each year plants of each cultivar were transplanted into their respective plots in late May, soil samples were collected in September prior to the removal of plants from each plot, and soil samples were collected again from each plot the following spring (April). Recommended practices for tobacco production were followed, except that the plants were not topped (flower heads removed), and no chemicals were applied to prevent growth of axillary buds at leaf nodes.

Inoculum density of $P$. parasitica var. nicotianae was determined for all plots in the fall and spring. In addition, isolates obtained from the mixed race plots were screened for race to determine the percent-

Table 1. Incubation period for aboveground symptoms of black shank on four tobacco cultivars that vary in level of partial resistance when inoculated with groups of isolates of either race 0 or 1 of Phytophthora parasitica var. nicotianae

\begin{tabular}{|c|c|c|c|c|}
\hline \multirow[b]{3}{*}{ Isolate group ${ }^{y}$} & \multicolumn{4}{|c|}{ Incubation period (days) $^{w}$} \\
\hline & \multicolumn{4}{|c|}{ Cultivar $^{\mathrm{x}}$} \\
\hline & Hicks & K326 & K149 & K346 \\
\hline Race 0 (K346) & $7 b^{z}$ & $14 \mathrm{c}$ & $16 \mathrm{~b}$ & $18 \mathrm{~b}$ \\
\hline Race 0 (K326) & $12 \mathrm{a}$ & $16 \mathrm{~b}$ & $18 \mathrm{a}$ & $21 \mathrm{a}$ \\
\hline Race 1 (NC71) & $13 \mathrm{a}$ & $17 \mathrm{a}$ & $19 \mathrm{a}$ & $>21$ \\
\hline
\end{tabular}

${ }^{\text {w }}$ Five-week-old plants were inoculated with colonized oat grains and observed over a 21-day period following inoculation, and the time required for expression of first visible symptoms was recorded. Data represent the mean of 20 isolates per race category.

${ }^{x}$ Hicks, susceptible; K326, low level of partial resistance; K149, moderate level of partial resistance; and K346, high level of partial resistance.

${ }^{\mathrm{y}}$ Isolates were collected using a soil assay from field plots planted to the cultivars K346 (high level of partial resistance), K326 (low level of partial resistance), or NC71 (completely resistant to race 0 and a low level of partial resistance). The isolates were further characterized as race 0 or race 1 using a host differential.

${ }^{\mathrm{z}}$ Incubation period data in each column followed by the same letter do not differ significantly (WallerDuncan $k=100$ ). Incubation period data for race 1 isolates on cultivar K 346 were not included in the statistical analysis, as those plants did not exhibit symptoms on the last day of tests and were given a rating $>21$ days. samples after correcting for soil moisture. For race determination in the mixed race plots, a minimum of 10 colonies from each plot, for a total of 180 colonies per treatment, were transferred to fresh PARPH, and additional transfers were made to obtain pure cultures of $P$. parasitica var. nicotianae. If 10 propagules per gram were not recovered from the initial soil assay, the soil was assayed additional times until 10 propagules were recovered from each plot, but population data were taken only from the initial assay. All isolates also were plated on nutrient agar to test for the presence of bacteria prior to transfer to $5 \%$ clarified carrot agar. Carrot juice (Hollywood or The Hain Celestial Group Inc., Melville, NY) was clarified by filtering the juice through diatomaceous earth (Celite 545, Fisher Scientific, Fair Lawn, NJ). Fifty milliliters of the filtrate was added to $950 \mathrm{ml}$ of deionized water and $20 \mathrm{~g}$ of Bacto Agar (Difco, Detroit, MI) and then sterilized in an autoclave prior to pouring.

To determine the race of each isolate, a host differential was used that included four cultivars or breeding lines: 'Hicks' (susceptible), 'K 326' (low level of partial resistance), 'NC 1071' (N. plumbaginifolia gene), and 'Ky $14 \times \mathrm{L} 8$ ' ( $N$. longiflora gene) (37). Plants of each differential were seeded into a flat containing potting mix (Metro mix 220) and allowed to grow 3 weeks. After 3 weeks, the plants were transplanted into cell packs ( 72 cells, $4 \times 4$ $\times 5 \mathrm{~cm})$ containing a $1: 1: 1(\mathrm{vol} / \mathrm{vol} / \mathrm{vol})$ mixture of steam-pasteurized soil, Metro mix (W. R. Grace), and coarse builder's sand. All plants were watered daily, fertilized as necessary with 20-20-20 water soluble fertilizer (Peter's), and allowed to grow an additional 7 to 10 days before inoculation.

Inoculum was prepared as described above, and 24 oat grains were removed from each plate using sterile technique and used as inoculum for race determination. Three 4-week-old plants of each genotype were root inoculated with each isolate in the greenhouse by placing two colonized oat grains into each $4 \times 4 \times 5 \mathrm{~cm}$ cell. Roots were not damaged prior to inocula-

Table 2. Severity index on four tobacco cultivars that range from susceptible to highly resistant when inoculated with isolates of race 0 or 1 of Phytophthora parasitica var. nicotianae

\begin{tabular}{|c|c|c|c|c|c|c|c|c|}
\hline \multirow[b]{3}{*}{ Isolate group $^{x}$} & \multicolumn{4}{|c|}{ Trial 1} & \multicolumn{4}{|c|}{ Tria1 2} \\
\hline & \multicolumn{4}{|c|}{ Cultivar ${ }^{w}$} & \multicolumn{4}{|c|}{ Cultivar } \\
\hline & Hicks $^{\mathrm{y}, \mathrm{z}}$ & K326 & K149 & K346 & Hicks & K326 & K149 & K346 \\
\hline Race 0 (K346) & $6.68 \mathrm{a}$ & $3.92 \mathrm{a}$ & $3.50 \mathrm{a}$ & $2.84 \mathrm{a}$ & $6.90 \mathrm{a}$ & $4.20 \mathrm{a}$ & $3.70 \mathrm{a}$ & $3.08 \mathrm{a}$ \\
\hline Race 0 (K326) & $4.78 \mathrm{~b}$ & $3.48 \mathrm{~b}$ & $2.88 \mathrm{~b}$ & $2.00 \mathrm{~b}$ & $4.92 \mathrm{~b}$ & $3.64 \mathrm{~b}$ & $3.32 \mathrm{~b}$ & $2.22 \mathrm{~b}$ \\
\hline Race 1 (NC71) & $4.42 \mathrm{~b}$ & $3.14 \mathrm{c}$ & $2.66 \mathrm{~b}$ & $0.00 \mathrm{c}$ & $4.54 \mathrm{c}$ & $3.34 \mathrm{c}$ & $2.82 \mathrm{c}$ & $0.00 \mathrm{c}$ \\
\hline
\end{tabular}

${ }^{\text {w}}$ Hicks, susceptible; K326, low level of partial resistance; K149, moderate level of partial resistance; and K346, high level of partial resistance.

${ }^{\mathrm{x}}$ Isolates were collected using a soil assay from field plots planted to cultivars K346 (high level of partial resistance), K326 (low level of partial resistance), or NC71 (completely resistant to race 0 and a low level of partial resistance). Isolates were further characterized as race 0 or race 1 using a host differential.

${ }^{y}$ Five- to six-week old plants of each cultivar were inoculated with colonized oat grains of a given isolate and observed over a 21-day period. Time required for the expression of first visible symptoms was recorded. Time to symptom expression was then converted to a disease index on a 0 to 10 scale, which represented both the time to symptoms and severity of symptoms. The scale is as follows: 3 days $=10,5$ days $=8,7$ days $=6,14$ days $=4,21$ days $=2$, no symptoms at day $21=0$. Data represent the mean of 20 isolates per race category and are averages over two trials.

${ }^{\mathrm{z}}$ Severity values in each column followed by the same letter do not differ significantly (Waller-Duncan $k=100$ ). 
tion. After 14 days, plants were scored for the presence or absence of symptoms, and the isolate was determined to be either race 1 or race 0 . Race 1 was defined by the ability to cause disease on 'NC 1071' and 'Ky $14 \times$ L8'. Race 0 did not cause disease on either of these hosts, but caused disease on the other two, 'Hicks' and 'K 326'. Race 1 also caused disease on 'Hicks' and 'K 326'.

Percent survival of the pathogen was calculated by dividing the inoculum density (ID) in the spring sample by the ID in the fall sample and multiplying by 100 . For the mixed race plots, race determinations were used to determine what percentage of the total pathogen population recovered could be attributed to each race. Analysis of variance was performed on the percent survival data using the PROC GLM procedure of SAS (version 8e), and means separation was conducted using the Waller-Duncan $k$-ratio test $(k=100)$. Unless otherwise indicated, only significant $(P \leq 0.05)$ differences between treatment means are presented.

\section{RESULTS}

Aggressiveness study. Significant variations were observed in aggressiveness between the groups of isolates representing races 0 and 1 . These differences occurred in all fitness parameters measured, including incubation period, disease severity index, root rot, and stunting. Significant variation also was observed between the two groups of race 0 isolates for these same measures of fitness.

As the level of partial resistance in the four tobacco cultivars increased, the incubation period increased for all isolate groups (Table 1). Differences were observed between groups in incubation period, but there was no cultivar by isolategroup interaction $(P>0.4)$; race 0 isolates from ' $\mathrm{K} 346$ ' caused symptoms faster than race 0 isolates from ' $K 326$ ' and race 1 isolates on each cultivar (Table 1). For example, on the susceptible 'Hicks', race 0 isolates from ' $\mathrm{K}$ 346' caused symptoms in 7 days, while race 0 isolates from ' $\mathrm{K} 326$ ' caused symptoms in 12 days and race 1 isolates caused symptoms in 13 days. Race 1 isolates did not cause symptoms on ' $\mathrm{K}$ 346' during the 21-day observation period. Similar results were observed in the second trial, but time to initial symptom development on average occurred 1 day earlier in all treatments (data not shown).

When incubation period data were converted to a severity index, there was a significant effect of trial, but within each trial there was a significant interaction between isolate group and cultivar. Therefore, data are shown by trial and significant differences are shown by isolate group on each cultivar (Table 2). The severity index increased for all isolate groups as the level of partial resistance decreased. Differences in severity index were observed between groups, with race 0 isolates from ' $\mathrm{K} 346$ ' having higher severity indices than race 0 isolates from ' $\mathrm{K} 326$ ' and race 1 isolates. For example, on the susceptible 'Hicks', race 0 isolates from ' $\mathrm{K} 346$ ' had a severity index of 6.68 , race 0 isolates from ' $\mathrm{K} 326$ ' had an index of 4.78 , and race 1 isolates had index value of 4.42. Again, ranking of isolate groups remained constant across the four levels of partial resistance. Differences were also observed within race 0 isolates, where those collected from ' $\mathrm{K}$ 346 ' had higher severity indices than race 0 isolates from ' $\mathrm{K}$ 326'. Race 1 isolates did not cause symptoms on ' $\mathrm{K}$ 346' and thus had severity indices of 0.00 in both trials.

Distribution of severity indices also varied within each isolate group (Fig. 1A to C). All isolates, except for race 1 isolates on ' $\mathrm{K} 346$ ', had a severity index of 2 or greater on all tobacco cultivars (Fig. 1A).

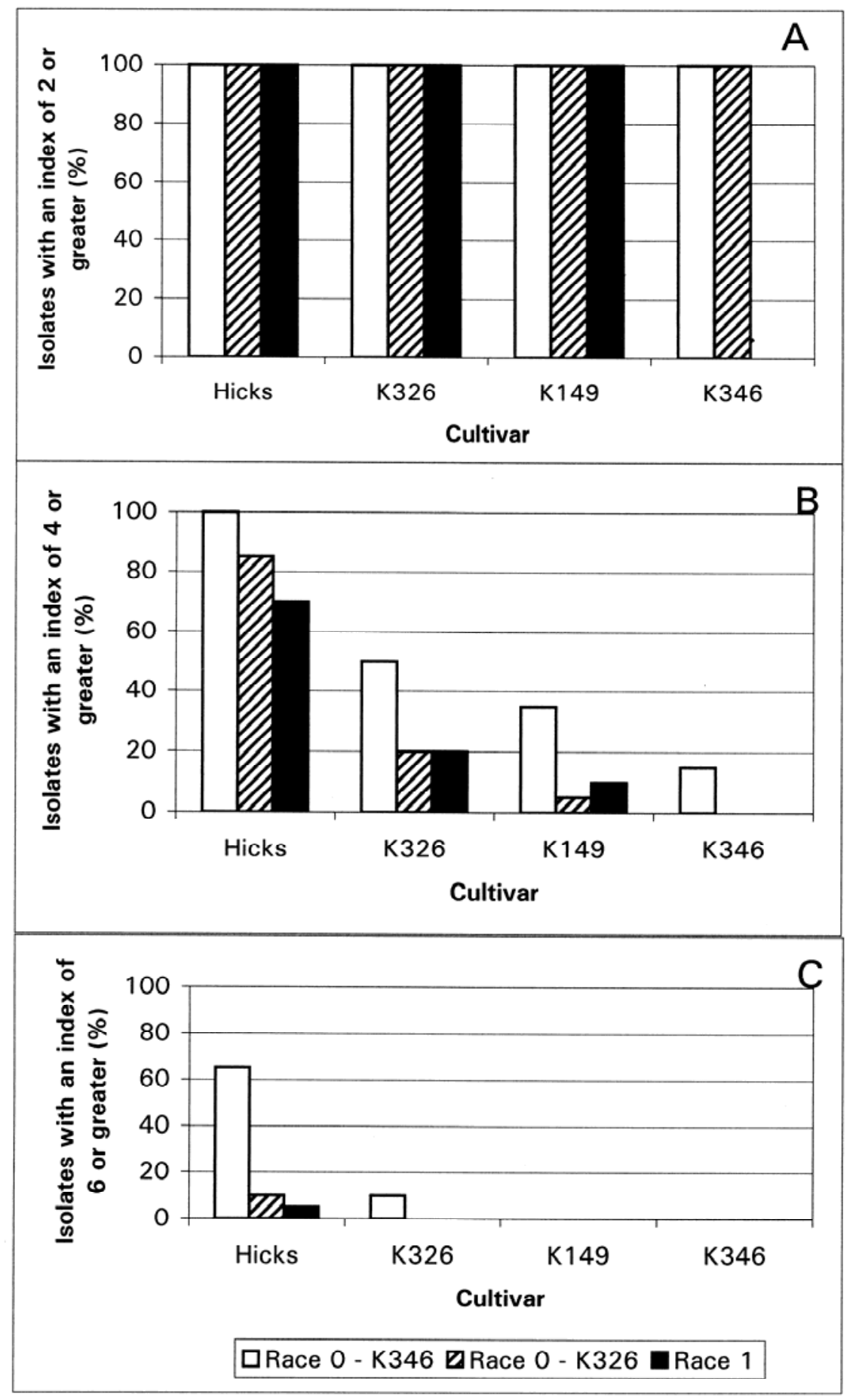

Fig. 1. Percentage of isolates in each isolate group with severity indices ( 0 to 10 scale) of $\mathbf{A}, 2, \mathbf{B}, 4$, or C, 6 on tobacco cultivars Hicks (susceptible), K326 (low level of partial resistance), K149 (moderate level of partial resistance), and K346 (high level of partial resistance). A severity index was based on number of days to symptom development: $2=15$ to 21 days, $4=8$ to 14 days, and $6=1$ to 7 days. 
However, only race 0 isolates from ' $\mathrm{K} 346$ ' had severity index values of 4 or greater on all four tobacco cultivars. Less than $10 \%$ of race 0 isolates from ' $\mathrm{K} 326$ ' and race 1 isolates had an index of 4 on the moderately resistant 'K 149' (Fig. 1B). On the susceptible 'Hicks', an index of 6 was observed for 65,10 , and $5 \%$ of race 0 isolates from ' $\mathrm{K}$ 346 ', race 0 isolates from ' $\mathrm{K} 326$ ' and race 1 isolates, respectively, (Fig. 1C).

There was not a significant effect of trial on root rot severity, so data were combined from the two runs of the experiment. There was a significant cultivar $\times$ race interaction $(P<0.001)$, so data are shown for each isolate group by cultivar. There was little or no difference among isolate groups in root rot severity on the susceptible cultivar or the cultivar with the low level of partial resistance (Fig. 2A and B). However, race 0 isolates had significantly more root rot than race 1 isolates on cultivars with moderate and high levels of partial resistance (Fig. 2C and D).
There was a significant effect of trial on stunting; plants grew less overall and had slightly less stunting in trial two. However, trends were similar across trials, so only data from the first trial are presented (Fig. 3 ). There was no significant difference in stunting on the susceptible 'Hicks', or on 'K 326' with low partial resistance (Fig. $3 \mathrm{~A}$ and $\mathrm{B}$ ). In sharp contrast to observations on root rot, race 1 isolates caused more stunting than either group of race 0 isolates on the moderately resistant ' $\mathrm{K}$ 149 ' and highly resistant ' $\mathrm{K}$ 346' (Fig. 3C and D). Race 0 isolates from ' $K$ 346' caused more stunting than did race 0 isolates from 'K 326'. Although most cultivars were stunted 60 to $80 \%$ relative to control plants, stunting of 'K326' was only about $30 \%$ with all isolate groups (Fig. 3B).

Survival study. Race 0 populations exceeded race 1 populations at every time point in the mixed-race plots from the microplot experiment. This was true for the plots planted with the cultivars with low or high partial resistance (Fig. 4A). In sharp contrast, on the completely resistant 'NC 71', race 1 populations exceeded race 0 populations at every time point (Fig. 4B). Race 0 populations declined steadily in plots planted with ' $\mathrm{NC}$ 71' and in the spring of 2003 was not detected (Fig. 4B).

Populations of both races declined sharply over each winter (Fig. 5A and B). Differences in survival were observed for the races. For example, in the mixed race plots, where survival data could be combined over the 2 years, race 0 isolates survived significantly better than race 1 isolates (Fig. 5B). On average, $60 \%$ of the race 0 population survived the winter, while only $42 \%$ of the race 1 population survived. In the single race plots, where there was a significant year and year $\times$ race interaction, data could not be combined over years, and differences in survival followed the same trend but were not significantly different (Fig. 5A).

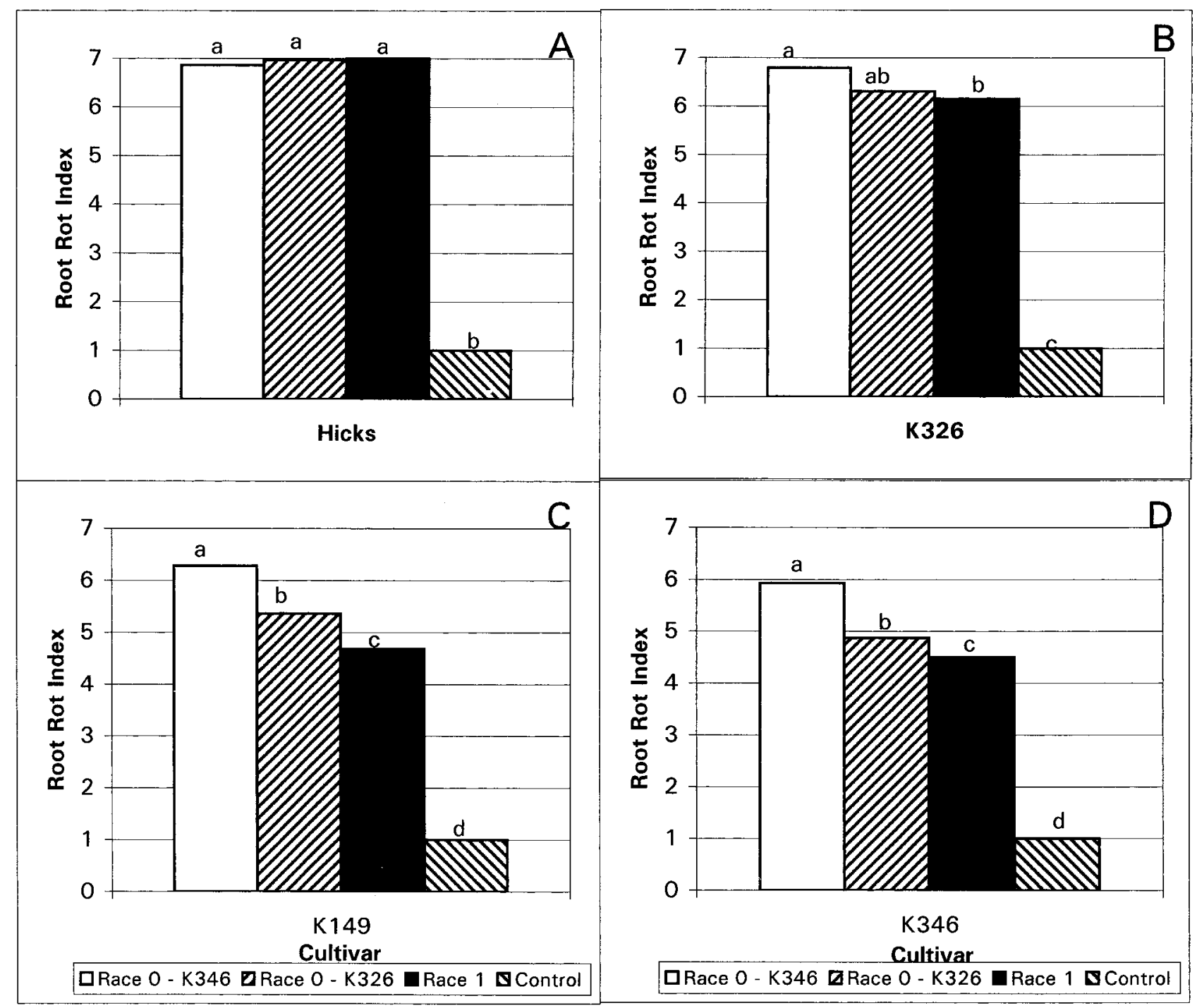

Fig. 2. Root rot caused by Phytophthora parasitica var. nicotianae on four tobacco cultivars with different levels of partial resistance: A, susceptible, B, low level, $\mathbf{C}$, moderate level, and $\mathbf{D}$, high level of resistance to black shank of tobacco. Bars are the average of five replications per treatment. Bars with the same letter do not differ significantly (Waller-Duncan $k=100$ ). 


\section{DISCUSSION}

Isolates of races 0 and 1 of $P$. parasitica var. nicotianae exhibited significant differences in aggressiveness on $N$. $t a$ bacum cultivars with different levels of partial resistance. Differences in incubation period, disease severity index, and root rot severity were observed. Variations in aggressiveness among isolates of race 0 of $P$. parasitica var. nicotianae have been reported $(2,22,42)$, but this is the first report where variations in aggressiveness between races of the tobacco black shank pathogen have been quantified. Similar observations were reported for races 1 and 2 of Verticillium dahliae, where isolates of race 1 caused greater losses than race 2 on cultivars susceptible to both races. For both pathogens, the ability to overcome resistance genes in the host was associated with a measurable loss in aggressiveness on susceptible cultivars $(6,41)$.
The time from inoculation to initial aboveground symptom development increased as the level of resistance in the tobacco cultivars increased for all isolate groups examined. This result indicated that the cultivars used in this study behaved in the greenhouse as they have previously reacted in fields infested with $P$. parasitica var. nicotianae. The resistance level (low to high) is generally assigned by extension specialists based on disease development in field trials over many locations and years. The ranking of isolate groups was similar across all cultivars, indicating that the isolates varied only in aggressiveness and not in virulence to the tobacco cultivars (41).

Differences between groups of race 0 isolates collected from ' $\mathrm{K} 326$ ' or ' $\mathrm{K} 346$ ' plots were observed in this study. Dukes and Apple (13) demonstrated that aggressiveness of isolates increased after passage through a resistant cultivar compared to passage through a susceptible cultivar. Their study suggested that under field conditions the pathogen strains would become more aggressive as a result of continuous planting of resistant cultivars. ' $\mathrm{K} 346$ ' has a high level of partial resistance compared with ' $\mathrm{K} 326$ ', which has a low level of partial resistance. The 20 isolates that comprised an isolate group in this study were collected from plots during the fourth year of a cultivar-rotation study, where either ' $\mathrm{K} 346$ ' or ' $\mathrm{K} 326$ ' was continuously cropped. Since 'K 346' has a higher level of resistance than ' $K$ 326', the higher level of aggressiveness observed in this isolate group supports the results of Dukes and Apple (13). The components of aggressiveness described by Dukes and Apple (14) were not quantified for the isolates in this study.

Race 1 caused significantly more stunting than either group of race 0 isolates, even though the race 0 isolates were more

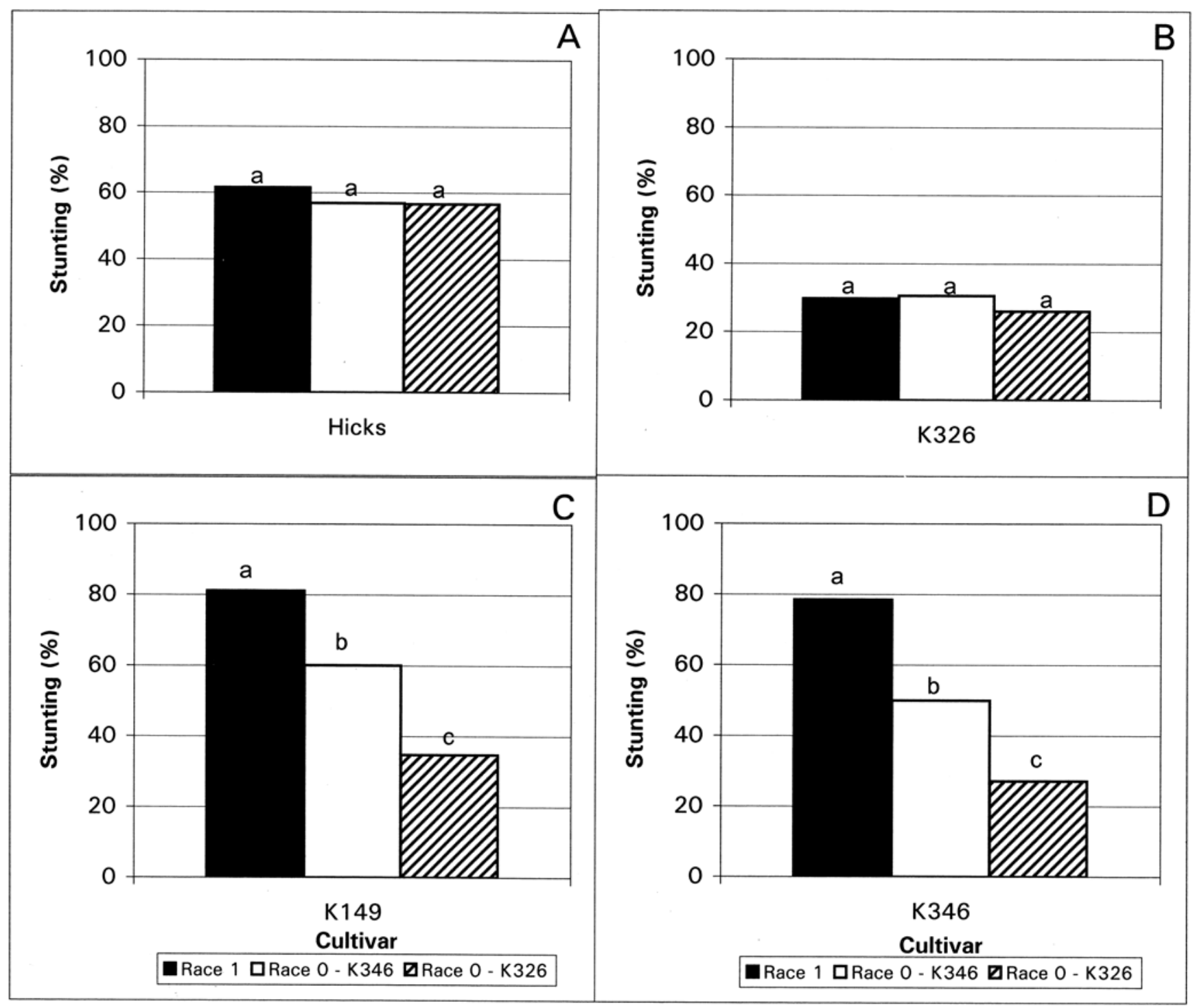

Fig. 3. Stunting caused by groups of isolates of races 0 or 1 of Phytophthora parasitica var. nicotianae. Percent stunting was relative to noninoculated control plants of the four cultivars with different levels of partial resistance: A, susceptible, B, low level, $\mathbf{C}$, moderate level, and $\mathbf{D}$, high level to black shank of tobacco. Bars are the average of five replications per treatment. Bars with the same letter do not differ significantly (Waller-Duncan $k=100$ ). 


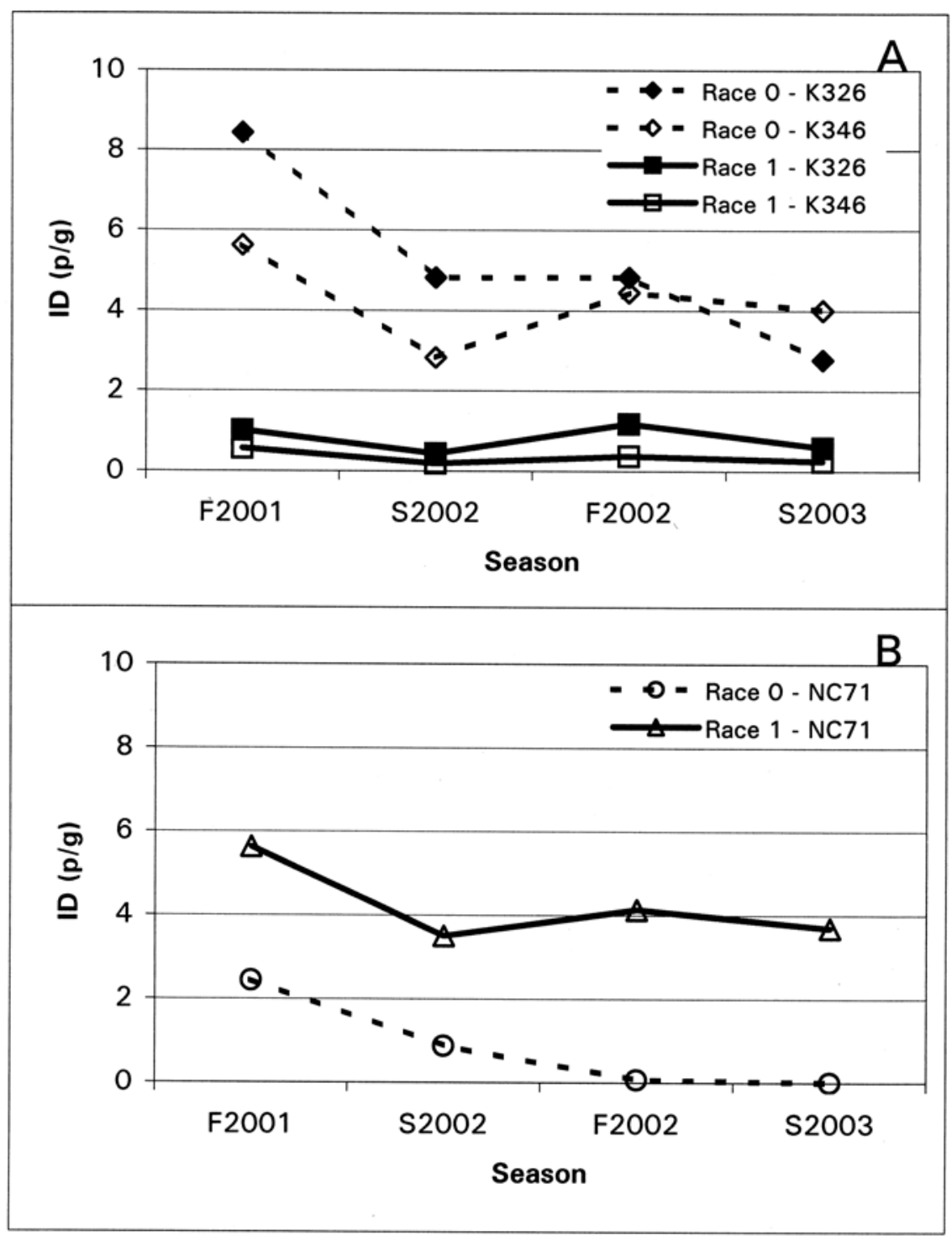

Fig. 4. Population dynamics of Phytophthora parasitica var. nicotianae in field microplots planted with tobacco cultivars A, K 326 (low partial resistance) or K 346 (high partial resistance), or B, NC71 (complete resistance) in mixed-race plots. Plots were originally infested with equal levels of races 0 and 1 .

aggressive in all other measures of disease development. Similar results were obtained by Carlson et al. (8), where a race 0 isolate of $P$. parasitica var. nicotianae caused symptoms faster, and disease severity was greater, than with a race 1 isolate. The race 1 isolate, however, caused significant plant stunting, reduced quality, and weakened root systems (8). The mechanisms of pathogenicity have not been investigated for race 0 and race 1 isolates, and deserve further study.

The cultivar with the low level of partial resistance, 'K 326', was only stunted $30 \%$ on average, while most other cultivars were stunted 50 to $80 \%$, with the exception of ' $\mathrm{K} 346$ ' inoculated with race 0 from ' $\mathrm{K}$ 326'. ' $\mathrm{K} 149$ ' and ' $\mathrm{K}$ 346' have moderate and high levels of partial resistance, respectively. Jones and Shew (18) showed that 'Hicks' and ' $\mathrm{K}$ 326' had significantly larger root systems (two to three times deployed in host cultivars. Even though partial resistance was effective against both races 0 and 1 of $P$. parasitica var. nicotianae, race 0 had a higher inoculum density than did race 1 . This result also indicated that race 1 was not as fit as race 0 on cultivars with partial resistance. By simply examining the population dynamic curves, however, it was not possible to ascertain if the difference was due to differences in initial inoculum density (survival) as Ferrin and Mitchell (16) suggested as being important or if it was due to differences in aggressiveness.

On the cultivar with complete resistance to race 0 , race 1 , by far, had the highest inoculum density at all sampling dates. Race 1 is able to reproduce on 'NC 71', and thus the curve takes into account survival, reproduction, and pathogenic potential. Race 0 , in sharp contrast, cannot reproduce on 'NC 71', and thus this curve represents a survival curve in the absence of new reproduction. The increase in race 1 relative to race 0 on the completely resistant cultivar can be explained by examination of the mechanism of resistance. Complete resistance does not prevent infection, but it prevents growth and reproduction of the pathogen, which results in a sharp decline in the pathogen population (35). A similar phenomenon has been observed with Thielaviopsis basicola on tobacco cultivars with the $N$. debneyi gene for complete resistance (36). Reproduction of $T$. basicola was very low or nonexistent on cultivars with resistance from $N$. debneyi. $P$. parasitica var. nicotianae can survive in soil for 5 years or longer in the absence of tobacco $(4,22)$. Our results indicate that propagules persisted for at least 3 years, because the plots were established in May 2000 and the final samples were collected in the spring of 2003.

The increase in predominance of race 1 of $P$. parasitica var. nicotianae in the fluecured region of North Carolina has corresponded with the widespread deployment of cultivars with the $P h$ gene, which confers complete resistance to race 0 of the pathogen. Race 0 is not able to reproduce on cultivars with the $P h$ gene, and thus race 1 has a selective advantage that allows it to become the predominant member of the population during continuous use of complete resistance. Our results demonstrate that isolates of race 1 are less fit than isolates of race 0 .

Simply defined, fitness is the combined ability of an organism to survive and reproduce. Vanderplank (41) considered pathogen fitness to be the driving force in the evolution and stability of a pathosystem in agriculture. He argued that in a freely mutating system, unnecessary virulence genes impose a fitness penalty to the pathogen. He suggested that a mutation from avirulence to virulence would only occur if it was necessary to overcome an $\mathrm{R}$ gene, i.e., if it was the only way the patho- 


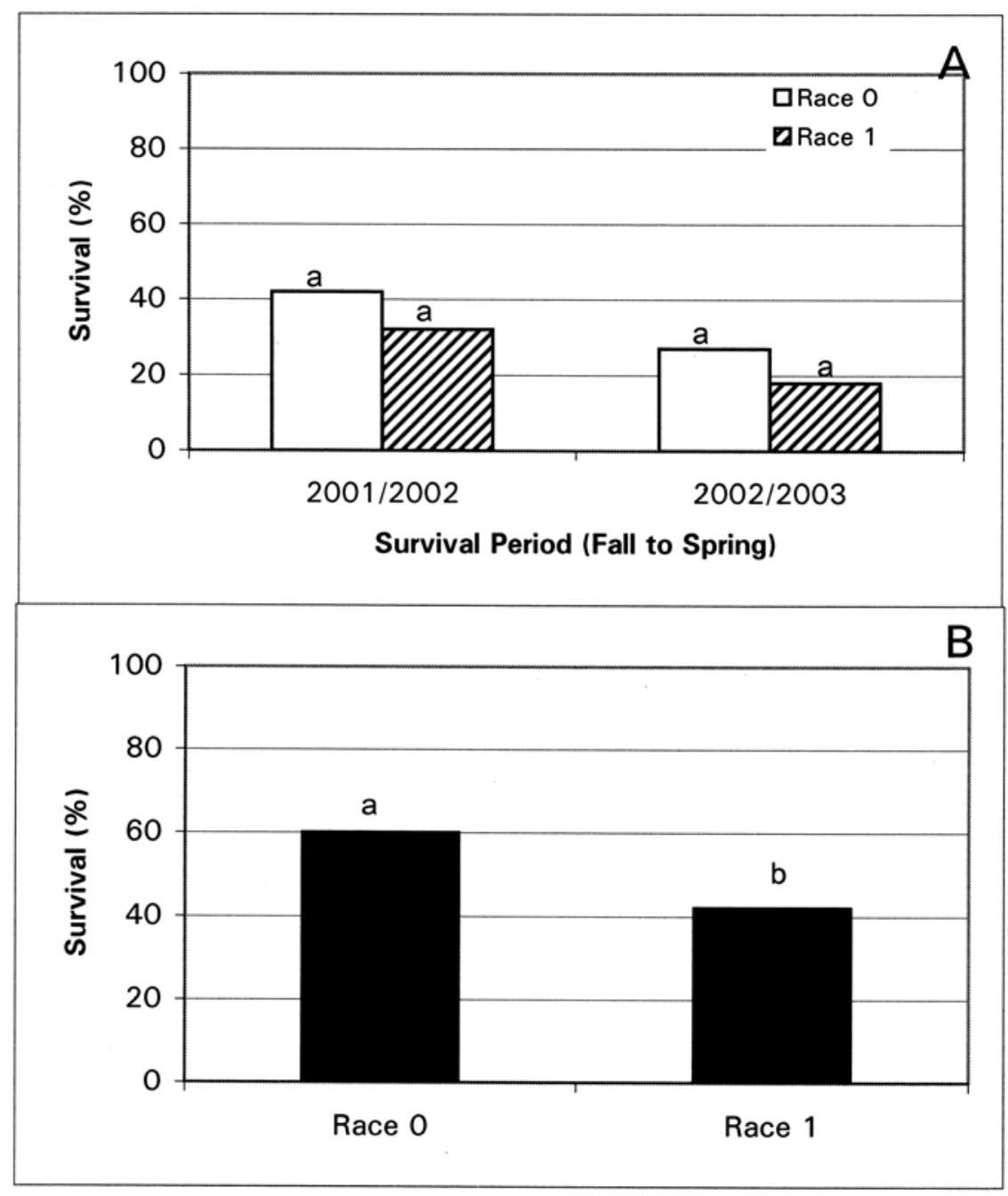

Fig. 5. Survival of races 0 and 1 of the tobacco black shank pathogen over two winters in plots infested with $\mathbf{A}$, a single race, or $\mathbf{B}$, a mixture of both races on cultivar K 326 (low level of partial resistance). Percent survival is based on percentage of fall population recovered the following spring. Bars are the average of 16 (single race plots) to 18 (mixed race plots) replications per treatment. Statistical analysis was conducted by winter for the single race plots and across winters for the mixed race plots. Bars with the same letter do not differ significantly (Waller-Duncan $k=100$ ).

gen can survive or persist. Thus, with respect to a specific avirulence- $R$ gene interaction, Vanderplank predicted that a mutation to virulence is associated with an increase in fitness if the $\mathrm{R}$ gene is present. However, if the avirulence gene mutation also carries a fitness penalty, the pathogen will have a reduction in fitness on the host without the R gene.

Results of the present study suggest that the mutation in the avirulence gene in race 1 results in a fitness penalty that is readily quantifiable on cultivars without the $P h$ gene, i.e., on cultivars with only partial resistance. Interestingly, the reduced fitness also appears to have an effect on the survivability of race 1 isolates. A statistical difference in survival between the races was observed when race 1 isolates were combined with race 0 isolates. Although not statistically significant, race 0 isolates declined more slowly than race 1 isolates when only one race was used to infest soil. Although shifts in relative population of resistance to be effective the following year against the developing race 0 population.

\section{ACKNOWLEDGMENTS}

The authors appreciate the technical support provided by Derald Glover and Courtney Reuter. This research was funded in part by the NC Tobacco Research Commission, the NC Tobacco Foundation, Inc., and the N.C. Agricultural Research Service. The first author also gratefully acknowledges support from the E. G. Moss Graduate Fellowship during part of this project.

\section{LITERATURE CITED}

1. Apple, J. L. 1954. Variation in pathogenicity of Phytophthora parasitica var. nicotianae. Plant Dis. Rep. 38:774-776.

2. Apple, J. L. 1957. Pathogenic, cultural, and physiological variation within Phytophthora parasitica var. nicotianae. Phytopathology 47:733-740.

3. Apple, J. L. 1962. Physiological specialization within Phytophthora parasitica var. nicotianae. Phytopathology 52:351-354.

4. Apple, J. L. 1963. Persistence of Phytophthora parasitica var. nicotianae in soil. Plant Dis. Rep. 47:632-634.

5. Apple, J. L. 1967. Occurrence of race 1 of Phytophthora parasitica var. nicotianae in North Carolina and its implications in breeding for disease resistance. Tob. Sci. 11:79-83.

6. Bender, C. G., and Shoemaker, P. B. 1984. Prevalence of Verticillium wilt of tomato and virulence of Verticillium dahliae race 1 and race 2 in western North Carolina. Plant Dis. 68:305-309.

7. Cameron, D. R. 1959. The monosomics of Nicotiana tabacum. Tob. Sci. 3:164-166.

8. Carlson, S. R., Wolff, M. F., Shew, H. D., and Wernsman, E. A. 1997. Inheritance of resistance to race 0 of Phytophthora parasitica var. nicotianae from the flue-cured tobacco cultivar Coker 371-Gold. Plant Dis. 81:12691274.

9. Chaplin, J. F. 1962. Transfer of black shank resistance from Nicotiana plumbaginifolia to flue-cured N. tabacum. Tob. Sci. 6:184-189.

10. Csinos, A. S. 2005. Relationship of isolate origin to pathogenicity of race 0 and 1 of $P h y$ tophthora parasitica var. nicotianae on tobacco cultivars. Plant Dis. 89:332-337.

11. Csinos, A. S., Fortnum, B. A., Powell, N. T., Reilly, J. J., and Shew, H. D. 1984. Resistance of tobacco cultivars and candidate cultivars to Phytophthora parasitica var. nicotianae. Tob. Sci. 28:153-155.

12. Csinos, A. S., and Minton, N. A. 1983. Control of tobacco black shank with combinations of systemic fungicides and nematicides or fumigants. Plant Dis. 67:204-207.

13. Dukes, P. D., and Apple, J. L. 1961. Influence of host passage on virulence of Phytophthora parasitica var. nicotianae. Plant Dis. Rep. 45:362-365.

14. Dukes, P. D., and Apple, J. L. 1962. Relationship of zoospore production potential and zoospore motility with virulence in Phytophthora parasitica var. nicotianae. Phytopathology 52:191-193.

15. Erwin, D. C. 1983. Variability within and among species of Phytophthora. Pages 149165 in: Phytophthora: Its Biology, Taxonomy, Ecology, and Pathology. D. C. Erwin, S. Bartnicki-Garcia, and P. H. Tsao, eds. American Phytopathological Society, St. Paul, MN.

16. Ferrin, D. M., and Mitchell, D. J. 1986. Influence of initial density and distribution of inoculum on the epidemiology of tobacco black shank. Phytopathology 76:1153-1158.

17. Johnson, E. S., Wolff, M. F., Wernsman, E. A. Atchley, W. R., and Shew, H. D. 2002. Origin of the black shank resistance gene, $P h$, in to- 
bacco cultivar Coker 371-Gold. Plant Dis. 86:1080-1084.

18. Jones, K. J., and Shew, H. D. 1995. Early season root production and zoospore infection of cultivars of flue-cured tobacco that differ in level of partial resistance to Phytophthora parasitica var. nicotianae. Plant Soil 172:55-61.

19. Kannwischer, M. E., and Mitchell, D. J. 1978. The influence of a fungicide on the epidemiology of black shank of tobacco. Phytopathology 68:1760-1765.

20. Kim, E. S., and Hwang, B. K. 1992. Virulence to Korean pepper cultivars of isolates of Phytophthora capsici from different geographic areas. Plant Dis. 76:486-489.

21. Lee, B. K., Kim, B. S., Chang, S. W., and Hwang, B. K. 2001. Aggressiveness to pumpkin cultivars of isolates of Phytophthora capsici from pumpkin and pepper. Plant Dis. 85:497-500.

22. Lucas, G. B. 1975. Diseases of Tobacco. 3rd ed. Biological Consulting Associates, Raleigh, NC.

23. Matheron, M. E., and Matejka, J. C. 1990. Differential virulence of Phytophthora parasitica recovered from citrus and other plants to rough lemon and tomato. Plant Dis. 74:138140.

24. McIntyre, J. L., and Taylor, G. S. 1978. Race 3 of Phytophthora parasitica var. nicotianae. Phytopathology 68:35-38.

25. Melton, T. A., and Broadwell, A. 2003. Disease Management. Pages 142-166 in: Flue-Cured Tobacco Information. NC Coop. Ext. Serv. Bull. AG-187 (revised). North
Carolina State University, Raleigh.

26. Nolla, J. A. B. 1928. The black shank of tobacco in Porto Rico. J. Dep. Agric. Porto Rico 7:185-215.

27. Peters, R. D., Platt, H. W., Hall, R., and Medina, M. 1999. Variation in aggressiveness of Canadian isolates of Phytophthora infestans as indicated by their relative abilities to cause potato tuber rot. Plant Dis. 83:652-661.

28. Powers, H. R., Jr., and Lucas, G. B. 1952. Variation within Phytophthora parasitica var. nicotianae. Plant Dis. Rep. 36:335-336.

29. Prinsloo, G. C., and Pauer, D. C. 1974. Die identikikasie van rasse van Phytophthora nicotianae B de Haan var. nicotianae wat in SuidAfrika voorkom. Phytophylactica 6:217-220.

30. Purwantara, A., Flett, S. P., and Keane, P. 1998. Variation in pathogenicity among isolates of Phytophthora clandestina. J. Phytopathol. 146:587-591.

31. Robin, C., and Desprez-Loustau, M. L. 1998. Testing variability in pathogenicity of Phytophthora cinnamomi. Eur. J. Plant Pathol. 104:465-475

32. Shenoi, M. M., Abdul Wajid, S. M., Elias, N. A., and Bhaktavatsalam, G. 1985. Occurrence of a new race of Phytophthora nicotianae var. parasitica in Hunsur tract. Ind. Phytopathol. 38:537-539.

33. Shew, H. D. 1983. Effects of soil matric potential on infection of tobacco by Phytophthora parasitica var. nicotianae. Phytopathology 73:1160-1163.

34. Shew, H. D. 1987. Effect of host resistance on spread of Phytophthora parasitica var. nicotianae and subsequent development of tobacco black shank under field conditions. Phytopathology 77:1090-1093.

35. Shew, H. D., and Shew, B. B. 1984. Host Resistance. Pages 244-275 in: Epidemiology and Management of Root Diseases. C. L. Campbell and D. M. Benson, eds. SpringerVerlag, Heidelberg, Germany.

36. Shew, H. D., and Shoemaker, P. B. 1993. Effects of host resistance and soil fumigation on Thielaviopsis basicola and development of black root rot on burley tobacco. Plant Dis. 77:1035-1039.

37. Sullivan, M. J., Melton, T. A., and Shew, H. D. Managing the race structure of Phytophthora parasitica var. nicotianae with cultivar rotation. Plant Dis. In press.

38. Thomidis, T. 2003. Variability in pathogenicity among Greek isolates of Phytophthora cactorum for four peach rootstocks. Aust. J. Exp Agric. 43:99-103.

39. Tisdale, W. B. 1931. Development of strains of cigar wrapper tobacco resistant to black shank (Phytophthora nicotianae Breda de Haan). Fla. Agric. Exp. Stn. Bull. 226:1-45.

40. Valleau, W. D., Stokes, G. W., and Johnson, E M. 1960. Nine years' experience with the Nicotiana longiflora factor for resistance to Phytophthora parasitica var. nicotianae in the control of black shank. Tob. Sci. 4:92-94.

41. Vanderplank, J. E. 1984. Disease Resistance in Plants. Academic Press, Orlando, FL.

42. van Jaarsveld, E., Wingfield, M. J., and Drenth, A. 2002. Evaluation of tobacco cultivars for resistance to races of Phytophthora nicotianae in South Africa. J. Phytopathol. 150:456-462. 